\title{
OPEN Fabrication of solderable intense pulsed light sintered hybrid copper for flexible conductive electrodes
}

\author{
Yong-Rae Jang ${ }^{1}$, Robin Jeong ${ }^{2}$, Hak-Sung Kim ${ }^{1,3 \bowtie} \&$ Simon S. Park ${ }^{2 \bowtie}$
}

Additively printed circuits provide advantages in reduced waste, rapid prototyping, and versatile flexible substrate choices relative to conventional circuit printing. Copper (Cu) based inks along with intense pulsed light (IPL) sintering can be used in additive circuit printing. However, IPL sintered Cu typically suffer from poor solderability due to high roughness and porosity. To address this, hybrid Cu ink which consists of Cu precursor/nanoparticle was formulated to seed Cu species and fill voids in the sintered structure. Nickel (Ni) electroplating was utilized to further improve surface solderability. Simulations were performed at various electroplating conditions and Cu cathode surface roughness using the multi-physics finite element method. By utilizing a mask during IPL sintering, conductivity was induced in exposed regions; this was utilized to achieve selective Ni-electroplating. Surface morphology and cross section analysis of the electrodes were observed through scanning electron microscopy and a 3D optical profilometer. Energy dispersive X-ray spectroscopy analysis was conducted to investigate changes in surface compositions. ASTM D3359 adhesion testing was performed to examine the adhesion between the electrode and substrate. Solder-electrode shear tests were investigated with a tensile tester to observe the shear strength between solder and electrodes. By utilizing Cu precursors and novel multifaceted approach of IPL sintering, a robust and solderable $\mathrm{Ni}$ electroplated conductive Cu printed electrode was achieved.

Recent advancements in flexible electronics have made way for exciting developments in devices such as: radio frequency identification (RFID) tags ${ }^{1,2}$, flexible displays ${ }^{3-5}$, flexible organic light-emitting diode (OLED) ${ }^{6,7}$, flexible solar cells ${ }^{8,9}$, and wearable electronics ${ }^{10,11}$. This is possible through use of flexible polymer-based substrates that can accommodate large deformations without sustaining structural damage. Utilizing common polymers as substrates such as polyimide (PI), polyethylene terephthalate (PET), and polyethylene terephthalate glycol (PETG) provide a pathway to a wide variety of robust and cheap electronic devices. However, these polymers are susceptible to damage from high temperature processes due to their low glass-transition temperatures ranging as low as $67^{\circ} \mathrm{C}$. As a result, modern high-temperature photolithography processes can be incompatible with flexible polymers without additional processing.

Alternatively, printing and IPL-sintering loose conductive nanoparticles can produce highly conductive tracks without thermal damage to the substrate. This low-temperature process can be streamlined to just three stages: printing-sintering-diagnosis. Metallic nanoparticles (NPs) are of interest in printed electronics due to their high electrical conductivity and simple ink-phase synthesis which can be readily implemented into existing printing technologies such as inkjet. Sintering via IPL bypasses high temperature processing by using the surface plasmonic effect; during IPL irradiation, electrons on the surface of nanomaterials resonate at a frequency that collapses its surface energy and allows significant necking/densification within the loose particles ${ }^{12-14}$. This effect significantly reduces sintering temperature and time requirements, which would otherwise damage the flexible substrate and immensely increase the manufacturing cost of flexible electronics. Due to the high surface area to volume ratio inherent in NPs, oxidation of metals is a large concern. Thus, noble and highly conductive metallic NPs such as gold $(\mathrm{Au})$ and silver $(\mathrm{Ag})$ are often used; however, these precious metals are prohibitively expensive, and their cost is further increased when processed into nanoparticle form. Copper $(\mathrm{Cu})$ NPs are a lower cost option that still provides excellent electrical conductivity. To utilize $\mathrm{Cu}$-based inks, Cu's inherent susceptibility to oxidation must be addressed. IPL sintering has previously been utilized to reduce the Cu oxide shells by heat

\footnotetext{
${ }^{1}$ Department of Mechanical Engineering, Hanyang University, 222, Wangsimni-ro, Seongdong-gu, Seoul 04763, Republic of Korea. 'Department of Mechanical and Manufacturing Engineering, Schulich School of Engineering, University of Calgary, 2500 University Drive NW, Calgary, AB T2N 1N4, Canada. ${ }^{3}$ Institute of Nano Science and Technology, Hanyang University, 222, Wangsimni-ro, Seongdong-gu, Seoul 04763, Republic of Korea. ${ }^{\square}$ email: kima@hanyang.ac.kr; simon.park@ucalgary.ca
} 
generation from surface plasmonic resonance and photo-degradation of polymeric binders ${ }^{15}$. IPL thus provides electrically conductive and oxide species reduction that reduce $\mathrm{Cu}$ particles for a high-performance ink receptive of existing printing technologies ${ }^{16-18}$.

Challenges still occur with IPL sintered $\mathrm{Cu}$-inks in regard to their porosity, surface roughness, and mechanical strength. High porosity and surface roughness are of concern as it adversely affects solderability and thus inhibits integration with modern flexible printed circuit board (FPCB) manufacturing. Salam et al. ${ }^{19}$ confirmed that the poor solderability of printed $\mathrm{Cu}$ is due to its surface roughness and heterogeneity (mix of $\mathrm{Cu}$ and voids). In addition, polymeric binders are typically introduced to reduce copper oxides during IPL sintering. As polymeric binders thermally decompose, they leave behind pores which further increase the porosity issue of sintered nanoparticles ${ }^{20}$. Conventional sintering in powder metallurgy is done on previously pressed ('green') parts. These parts have already been compacted under high pressures which minimizes issues in final density and surface features. Compaction of printed-inks under high pressures, however, this adds further complexities and may damage the polymeric substrates. For these reasons, it has been difficult to realize the mass production of ink-printed electronic circuit components.

Electroplating is one method that can reduce surface roughness. Nickel (Ni) electroplating is an ideal candidate to provide a smooth, scratch-resistant, surface. A homogenous Ni surface facilitates good solderability while providing high mechanical strength without compromising electrical conductivity and oxidation susceptibility. Thus, a Ni plated printed $\mathrm{Cu}$ circuit produces a conductive, solderable (smooth surface), oxidation resistant, and mechanically resilient electrode ${ }^{21-24}$. However, Ni-electroplating deposition is limited to the surface and does not address internal porosity which can impair conductivity and adhesion to the polymeric substrate; in-addition, $\mathrm{Ni}$ deposition suffers from a lack of selectivity when presented with a conductive copper surface and is challenging to produce a desired circuit pattern. To address this, the initial non-conductive nature of unsintered inks can be utilized to form conductive and nonconductive patterns with selective exposure of IPL. By using a simple mask, an electrically conductive copper pattern is produced after IPL sintering; these patterns, specific to the electronic device or electrode requirements are sites of $\mathrm{Ni}$ electro-deposition while the non-conductive non-sintered regions do not participate in electroplating. This simple and selective plating of only IPL sintered tracks can be utilized to incorporate electroplating to the production of ink-based circuitry with minimal complexity.

In this study, solderability of printed and sintered $\mathrm{Cu}$ surfaces has been investigated by reducing internal porosity and surface roughness. To reduce internal porosity and surface roughness, $\mathrm{Cu}$ is seeded on $\mathrm{Cu}$ NPs. Chung et al. ${ }^{25}$ found that $\mathrm{Cu}$ precursors $\left(\mathrm{Cu}\right.$ (II) nitrate trihydrate, $\left.\mathrm{Cu}\left(\mathrm{NO}_{3}\right)_{2}\right)$ exposed to IPL irradiation thermally degrade and precipitate as $\mathrm{Cu}$ (I) oxide. By introducing polyvinylpyrrolidone (PVP), these oxide Cu seeds are thermally degraded during IPL sintering to produce a dense and smooth Cu electrode. In addition, IPL is utilized to produce a circuit pattern that is selectively plated by Ni electroplating to enhance solderability and mechanical strength. The present novel application of multifaceted IPL sintering is optimized through initial ink composition as well as sintering and electroplating parameters. To assist in the parametric study of Ni electroplating, multi-physics FEM simulations were conducted; evolution of the Ni surface roughness as well as deposit thickness at various current densities, plating times, and bath temperatures were noted during simulations and experimentally verified.

The goal of the present work is to create a solderable electrode manufactured from printable Cu NP based ink. By utilizing IPL sintering with $\mathrm{Cu}$ precursors followed by Ni electroplating, a robust smooth electrode was produced. Experiments were performed to reveal additional characteristics of the present electrode production process such as: resistivity of the $\mathrm{Cu}$ precursor/NP (CPN) electrode using the 4-probe method; and surface morphology and cross-sectional analysis using both a 3D optical profiler and SEM after Ni electroplating of the IPL sintered CPN electrodes. Solder shear tests and simulations were conducted to investigate the correlation between the surface roughness and solderability. In addition, the contact angle of the solder was measured to confirm the wettability of solder on each type of electrode. Selectivity tests were performed by exposing only half of the printed electrode surface to flash-sintering. The half-electrodes were electroplated at optimal conditions to observe selective plating of sintered portions. Based on these results, the process conditions for solderable IPL sintered $\mathrm{Cu}$ electrodes were established for electrical circuit manufacturing by printed electronics technology.

\section{Experiments}

A Cu-based conductive ink was fabricated by mixing the $\mathrm{Cu}$ NPs and $\mathrm{Cu}$ precursors. The $\mathrm{Cu}$ precursor/NP (CPN) ink was sintered with IPL irradiation followed by Ni electroplating (Fig. 1). Various properties of the Ni-electroplated CPN electrode were characterized to explore their effects on solderability.

Fabrication of Cu NPs ink \& Cu precursor/NPs (CPN) ink. For ink synthesis, poly(N-vinylpyrrolidone) (PVP, MW 55,000; Sigma Aldrich) (0.08 g) was dissolved in diethylene glycol (DEG, 99\%; Sigma Aldrich) $(1.08 \mathrm{~g})$ and ultra-sonicated for $1 \mathrm{~h}$. For Cu NPs ink, only Cu NPs (diameter, $50 \mathrm{~nm})(2.16 \mathrm{~g}$ ) were added to the PVP-DEG solution. For CPN ink, Cu NPs (diameter, $50 \mathrm{~nm})(2.16 \mathrm{~g})$, diethylene glycol butyl ether (DEGBE, 99\%; Sigma Aldrich) (0.47 g), and the PVP-DEG complex solvent were vortexed for $1 \mathrm{~min}$ followed by $20 \mathrm{~min}$ of ultra-sonication. $\mathrm{Cu}$ precursors $\left(\mathrm{Cu}\left(\mathrm{NO}_{3}\right)_{2}, 30\right.$ wt.\% of Cu NPs; Sigma Aldrich) (0.648 g) were dispersed in a prepared solvent using an ultra-sonicator for $1 \mathrm{~h}$ (see Table 1 ).

The CPN inks were printed using the doctor blade method using $50 \mu \mathrm{m}$ thick polyimide (PI) substrates as $5 \mathrm{~mm} \times 50 \mathrm{~mm}$ long tracks. The printed CPN ink was dried at $90^{\circ} \mathrm{C}$ for $10 \mathrm{~min}$ on a hot plate followed by drying under vacuum for $12 \mathrm{~h}$ to completely remove residual solvents. IPL sintering was carried out with Xenon S-2300 Dual-Stage Sintering System with IPL irradiation conditions (pulse on-time, $3 \mathrm{~ms}$; pulse number, 1; pulse energy, $3.04-5.88 \mathrm{~J} / \mathrm{cm}^{2}$ ) to achieve a final sintered thickness of $25 \mu \mathrm{m}$. Samples prepared for selective electroplating were masked with aluminium foil to expose only half of the printed electrodes to IPL. By utilizing a simple mask 


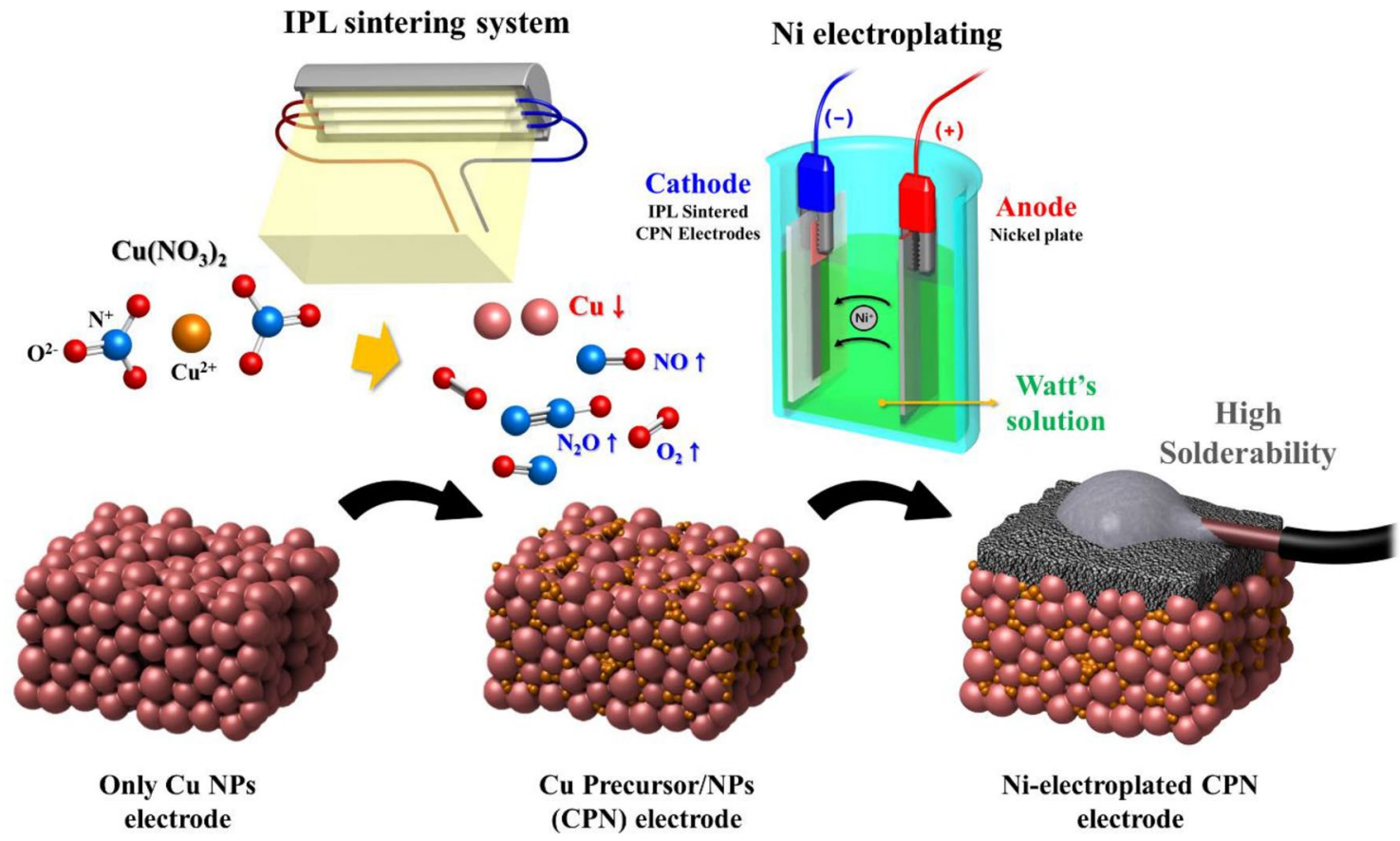

Figure 1. Highly solderable nickel electroplated Cu Precursor/NPs electrode.

\begin{tabular}{|l|l|l|l|}
\hline \multicolumn{2}{|l|}{$\begin{array}{l}\text { Cu NPs ink } \\
\text { composition }\end{array}$} & \multicolumn{2}{l|}{ CPN ink compositions } \\
\hline PVP & $0.08 \mathrm{~g}$ & PVP & $0.08 \mathrm{~g}$ \\
\hline DEG & $1.08 \mathrm{~g}$ & DEG & $1.08 \mathrm{~g}$ \\
\hline $\mathrm{Cu} \mathrm{NPs}$ & $2.16 \mathrm{~g}$ & DEGBE & $0.47 \mathrm{~g}$ \\
\hline & & $\mathrm{Cu} \mathrm{NPs}$ & $2.16 \mathrm{~g}$ \\
\hline & & $\mathrm{Cu}\left(\mathrm{NO}_{3}\right)_{2}$ & $0.648 \mathrm{~g}$ (30 wt.\% of Cu NPs) \\
\hline
\end{tabular}

Table 1. Material composition of Cu NPs ink and CPN ink.

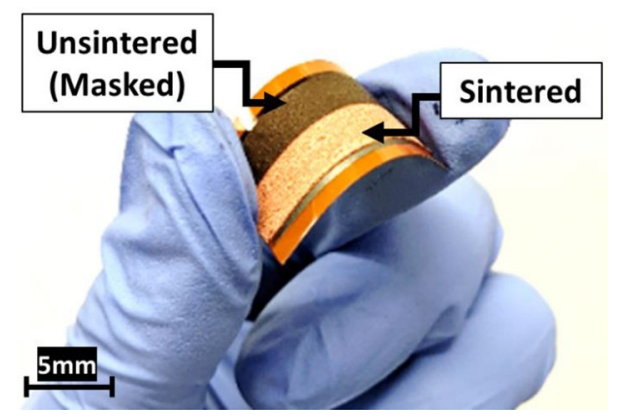

Figure 2. Half-sintered CPN ink flexible electrodes sintered at $2800 \mathrm{~V}$ for $3 \mathrm{~ms}\left(5.17 \mathrm{~J} / \mathrm{cm}^{2}\right)$ for selective electroplating investigations.

(demonstrated here with aluminium foil), electroplating can be incorporated to produce a conductive, solderable, and mechanically robust printed circuit (Fig. 2).

Nickel electroplating of CPN electrodes. A Watt's solution containing: nickel (II) chloride $\left(\mathrm{NiCl}_{2}\right.$; Sigma Aldrich) $(40 \mathrm{~g} / \mathrm{L})$, nickel (II) sulfate $\left(\mathrm{NiSO}_{4}\right.$; Sigma Aldrich) $(250 \mathrm{~g} / \mathrm{L})$ and boric acid $\left(\mathrm{H}_{3} \mathrm{BO}_{3}\right.$; Sigma Aldrich) $(45 \mathrm{~g} / \mathrm{L})$ was dispersed by sonicator for 24 hours $^{26,27}$ (Table 2). For better electrical conductivity, semibright Watt's solution was utilized. A nickel plate $(2 \mathrm{~cm} \times 8 \mathrm{~cm})$, and IPL sintered CPN on the polymeric substrate were wired as the anode and cathode, relatively. 2, 5, $10 \mathrm{~A} / \mathrm{dm}^{2}$ current densities were applied using a DC 


\begin{tabular}{|l|r|l|l|}
\hline \multicolumn{3}{|l|}{ Bath composition } & Operating conditions \\
\hline $\mathrm{NiCl}_{2}$ & $40 \mathrm{~g} / \mathrm{L}$ & Current density & $2,5,10 \mathrm{~A} / \mathrm{dm}^{2}$ \\
\hline $\mathrm{NiSO}_{4}$ & $250 \mathrm{~g} / \mathrm{L}$ & Time & $1,5,10 \mathrm{~min}$ \\
\hline $\mathrm{H}_{3} \mathrm{BO}_{3}$ & $45 \mathrm{~g} / \mathrm{L}$ & Bath Temp & $40,60{ }^{\circ} \mathrm{C}$ \\
\hline & & $p H$ & 3.2 \\
\hline & & Electrode distance & $1 \mathrm{~cm}$ \\
\hline
\end{tabular}

Table 2. Bath composition and operating conditions for semi-bright Watt's solution Ni electroplating.

power supply (Model 9103; 42 V/ 20 A/ 320 W; BK Precision). In addition, for a smoother electroplated Ni layer, plating time $(1,3,5 \mathrm{~min})$ and bath temperature $\left(40,60^{\circ} \mathrm{C}\right)$ were controlled. During the electroplating process, $\mathrm{pH}$ was fixed at 3.2 and the electrode distance between was fixed to $1 \mathrm{~cm}$.

A total of 18 electroplating conditions were explored and the surface roughness, thickness, and adhesion of the Ni layer on each electrode was measured. Surface roughness was measured using a 3D optical profiler (Zeta-20; Zeta Instruments). The thickness of the Ni layer was obtained by measuring the thickness of the CPN electrode prior to electroplating and then subtracted from the measured thickness after electroplating. For adhesion characterization, values from 0 to 5B were obtained through an ASTM D 3359 adhesion test. Following the ASTM D3359-B (the cross-cut tape test), each electrode was cut 6 times in both horizontal and vertical directions to form a total of 25 grids with sizes of $2 \mathrm{~mm} \times 2 \mathrm{~mm}$. It was cut by applying sufficient force so that it can be cut completely in the thickness direction of the electrode.

Characterizations. The electrical resistivity of IPL sintered Cu NP, CPN, and electroplated CPN electrodes was obtained by converting the sheet resistance measured through the 4-point probe method. For Ni-electroplated CPN, the sheet resistance was measured in the form of a double layer in which a Ni layer was applied on an uneven $\mathrm{Cu}$ electrode. Therefore, the resistivity was calculated after assuming the entire Ni-electroplated $\mathrm{CPN}$ electrode as a metal alloy. The CPN electrode had a resistivity of $12.2 \mu \Omega \cdot \mathrm{cm}$ sintered under the optimum IPL conditions (pulse on-time, $3 \mathrm{~ms}$; IPL energy density, $5.13 \mathrm{~J} / \mathrm{cm}^{2}$ ), and the resistivity of the entire electrode considering each thickness of the Ni layer was calculated.

Among the 18 cases of Ni-electroplated CPN electrodes, the highest quality specimens (s-16) were used to compare with Cu NP and CPN (non-plated) electrodes. 3D optical profiler (Zeta-20; Zeta Instrument) was utilized to observe the surface roughness of each specimen. A root-mean-square deviation of surface topography $\left(S_{q}\right)$ was measured to compare surface roughness. The surface roughness analysis area was $831 \mu \mathrm{m} \times 623 \mu \mathrm{m}$ with 200 height steps with a step size of $0.357 \mu \mathrm{m}$. Cross sectional analysis was performed to compare porosity and electroplating deposit characteristics. Each specimen was immersed in liquid nitrogen, frozen, and then broken to minimize deforming the cross-section of the specimen. The prepared specimens were subjected to SEM analysis to visually compare the packing density of each electrode layer. In the case of Ni electroplated CPN electrode, the distribution of surface components was identified through EDS analysis. To investigate the mechanical property of the Ni-electroplated CPN electrode as a FPCB, adhesion testing was conducted based on ASTM D3359.

Soldering on the Ni-electroplated CPN electrodes. Solder (Sn99-Ag-0.3-Cu0.7) was applied to test the solderability of three different kinds of electrodes (i.e., Cu NPs electrode, CPN electrode, and Ni-electroplated CPN electrodes). The contact angle between the molten solder droplet and each type of electrode was measured to compare the effect of surface roughness to solder wetting using a contact angle measurement system (Smartdrop; Femtofab Co.).

In addition, shear strength between solder and the electrode was measured with a tensile tester (ESM303, $1.5 \mathrm{kN}$; Mark-10). Using solder wire and a soldering iron at $250{ }^{\circ} \mathrm{C}$, a conductive wire was attached to the Nielectroplated CPN electrode. The shear tensile test was performed by fixing the wire and PI substrate to the tensile tester after the solder was firmly hardened. The area between solder and electrode was kept to $20 \mathrm{~mm}^{2}$ in all cases, and the test was conducted at a constant speed of $0.3 \mathrm{~mm} / \mathrm{min}$. The tensile test proceeded until the solder was completely stripped from the electrode, and the recorded stress at failure was compared.

Through the above experiments, it was confirmed that the surface morphology of the electrodes is changed, and the solderability is improved through addition of $\mathrm{Cu}$ precursors and Ni-electroplating.

\section{Finite element method (FEM) simulation of Ni electroplating}

Modelling for Ni electroplating on the CPN electrode and relationship between surface roughness and Nielectroplating parameters are presented in this section. Ni-deposit behaviour was studied using a multi-physics FEM software by approximating the surface of the CPN electrode as a continuous row of triangles with fillets. To achieve these simulations, the electrodeposition tool in Chemical Engineering Module was selected. The deposition of Nickel layer on the Cu electrode is one of the modeling methods of the electrodeposition process in multiphysics FEM: 'The standard model Copper Deposit in a Trench'. This simulation example is based on a research by Mattsson et al. ${ }^{28}$; where a rough copper electrode surface was applied to show how the Ni-electroplated surface developed depending on the cathode geometry as well as electrolyte composition.

To simulate the effect of initial cathode roughness on electroplating of $\mathrm{Ni}$, the geometry of the CPN electrode was varied as shown in Fig. 3a. The anode was placed at the upper boundary while the cathode (with various 
(a)

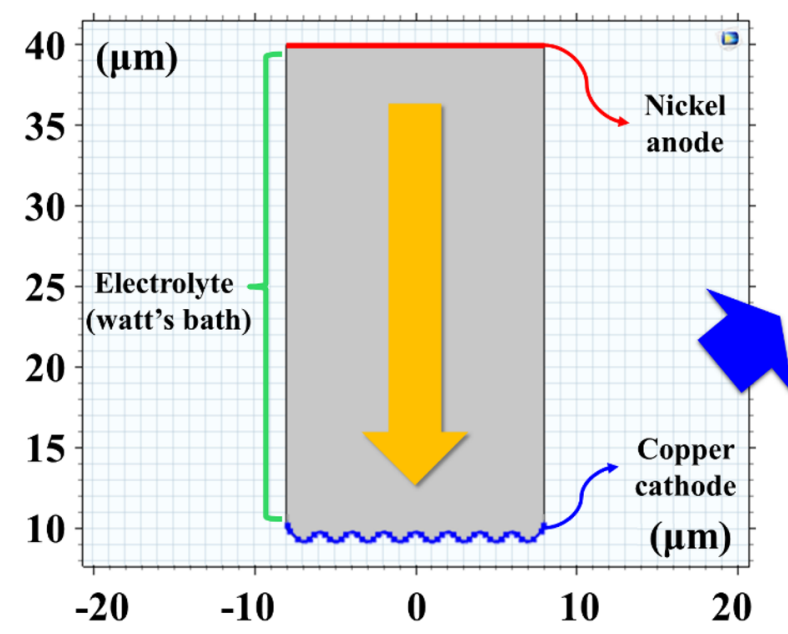

(b)

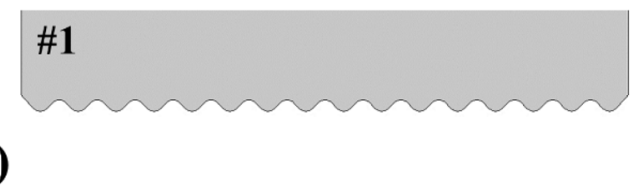

\#2

(d)

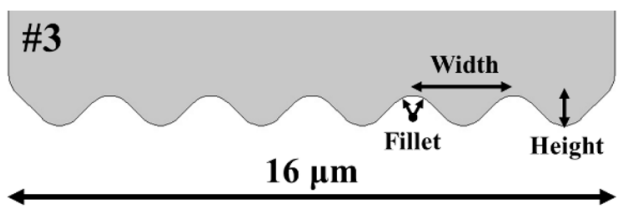

Figure 3. (a) The geometry of Ni electroplating model, and (b, c, d) the cathode electrode shape of 3 cases (dimensions are represented in Table 3).

\begin{tabular}{|l|l|l|l|}
\hline & $\# \mathbf{1}$ & $\mathbf{\# 2}$ & \#3 \\
\hline Triangle width $(\mu \mathrm{m})$ & 1.0 & 2.0 & 3.0 \\
\hline Triangle height $(\mu \mathrm{m})$ & 0.5 & 1.0 & 1.5 \\
\hline Fillet $(\mu \mathrm{m})$ & 0.25 & 0.5 & 0.75 \\
\hline RMS Roughness $(\mu \mathrm{m})$ & 0.097 & 0.194 & 0.394 \\
\hline
\end{tabular}

Table 3. Geometry dimensions and RMS roughness of cathode electrode.

roughnesses) was positioned at the lower boundary. To approximate surface roughness of sintered Cu particles the cathode was represented as a jigsaw shape composed of isosceles triangles. Furthermore, fillets were applied to the vertices of the aligned triangles (Fig. $3 b-d)$. The dimensions of each case and RMS roughness are shown in Table 3.

Through this approximation, multi-physics FEM electroplating simulation was performed at various cathode geometries. As $\mathrm{Ni}$ was electroplated, the effectiveness of surface smoothening by electroplating was determined according to 3 cases of simulated CPN electrodes.

There are several governing equations involved in the simulation process ${ }^{29,30}$. First, the vertical walls on the main electrode are considered isolated:

$$
N_{i} \times n=0
$$

Second, the flow for each of the ions in the electrolyte is determined by the Nernst-Planck equation:

$$
N_{i}=-D_{i} \nabla c_{i}-z_{i} u_{i} F c_{i} \nabla \phi_{l}
$$

where $N_{i}$ is transport vector $\left(\mathrm{mol} /\left(\mathrm{m}^{2} \cdot \mathrm{s}\right)\right), c_{i}$ is concentration in the electrolyte $\left(\mathrm{mol} / \mathrm{m}^{3}\right), z_{i}$ is the charge for the ionic species, $u_{i}$ is the mobility of the charged species $\left(\mathrm{m}^{2} /(\mathrm{s} \cdot \mathrm{J} \cdot \mathrm{mole})\right), F$ is Faraday's constant (As/mole), and $\phi_{l}$ is the potential in the electrolyte $(\mathrm{V})$. This equation allows us to calculate the distribution of Ni ion concentrations, iso-potential lines, current density lines, and displacements of the cathode and anode surfaces.

In order to model the electrokinetics of the present Ni-electroplating simulation, the Butler-Volmer equation was used ${ }^{31}$. This equation represents the relationship of the current density of the electrode to the electrode potential with respect to the cathodic and anodic reaction and is given by:

$$
i=i_{o}\left[\exp \left(-\frac{\alpha_{c} F_{\eta}}{R T}\right)-\exp \left(-\frac{\alpha_{a} F_{\eta}}{R T}\right)\right]
$$

where $i_{o}$ is exchange current density, $\alpha_{c}$ and $\alpha_{a}$ are cathodic \& anodic transfer coefficient, $\mathrm{F}$ is the Faraday's constant, $\eta$ is activation overpotential, and $\mathrm{R}$ is gas constant, respectively. The electrolyte initial condition and parameters of Ni electroplating model are in Table 4.

Thus, the thickness and shape of the electroplated Ni layer can be determined through simulations with respect to time. Therefore, the deposition and smoothening process of Ni layer can be predicted over time at various conditions of Ni-electroplating (ex. current densities and temperatures). By utilizing simulated results, optimal Ni-electroplating parameters were predicted prior to experimentation. 


\begin{tabular}{|l|l|l|}
\hline Parameter & Value & Description \\
\hline $\mathrm{E}_{\text {eq_}} \mathrm{Ni}$ & $-0.26(\mathrm{~V})$ & Equilibrium potential, nickel reaction \\
\hline $\mathrm{Kappa}$ & $10(\mathrm{~S} / \mathrm{m})$ & Electrolyte conductivity \\
\hline $\mathrm{M} \_\mathrm{Ni}$ & $58.69(\mathrm{~g} / \mathrm{mole})$ & Molar mass, nickel \\
\hline $\mathrm{M} \_\mathrm{Cu}$ & $63.55(\mathrm{~g} / \mathrm{mole})$ & Molar mass, copper \\
\hline $\mathrm{Rho} \_\mathrm{Ni}$ & $8908\left(\mathrm{~kg} / \mathrm{m}^{3}\right)$ & Density, nickel \\
\hline $\mathrm{Rho} \_\mathrm{Cu}$ & $8960\left(\mathrm{~kg} / \mathrm{m}^{3}\right)$ & Density, copper \\
\hline $\mathrm{i}_{\mathrm{o} \_} \mathrm{Ni}$ & $0.1\left(\mathrm{~A} / \mathrm{m}^{2}\right)$ & Exchange current density, nickel reaction \\
\hline $\mathrm{i}_{\mathrm{o} \_} \mathrm{H}$ & $2 \mathrm{E}-5\left(\mathrm{~A} / \mathrm{m}^{2}\right)$ & Exchange current density, hydrogen reaction \\
\hline
\end{tabular}

Table 4. The electrolyte initial condition and parameters of Ni electroplating model.

IPL voltage (V)

$\begin{array}{llllllll}1900 & 2100 & 2300 & 2500 & 2700 & 2900 & 3100\end{array}$

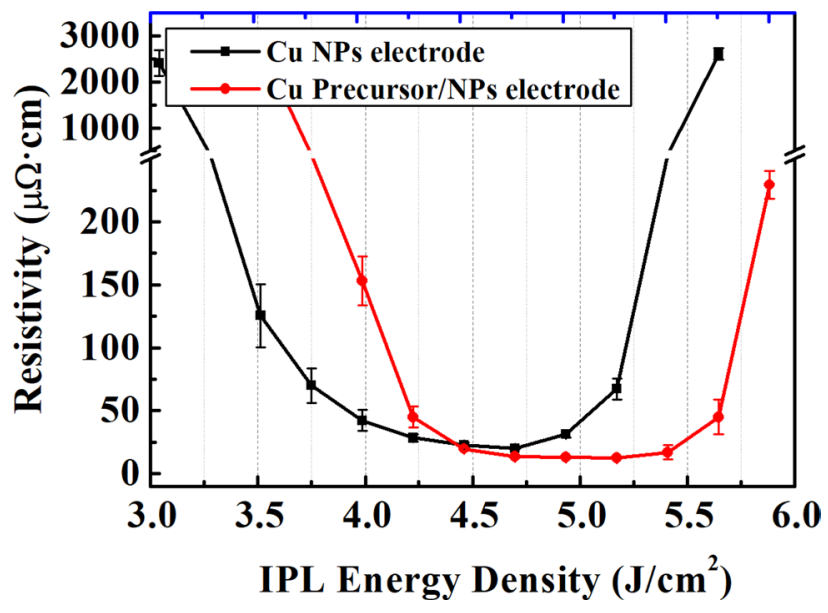

Figure 4. A plot of resistivity changes in $\mathrm{Cu}$ and $\mathrm{CPN}$ electrodes with respect to applied IPL irradiation energy.

\section{Results and discussions}

The evolution of surface roughness during Ni electroplating was optimized experimentally and compared to simulation results. By optimizing the electroplating parameters for the smoothest surface, solder adhesion is also expected to be optimized. In addition, various flash energies and their effect on the sintered structure was characterized. The effect of ink compositions and electroplated samples was investigated to provide insight of an individual components influence on final performance. Finally, a high-performance flexible printed track was produced with high solderability.

IPL sintering of the Cu NPs/precursor electrodes. From previous research, it was found that $\mathrm{Cu}$ precursor in an amount of $30 \mathrm{wt} . \%$ relative to $\mathrm{Cu}$ NPs has the highest electrical conductivity and packing density when sintered with IPL ${ }^{25}$. In accordance to the previous findings, $30 \mathrm{wt}$. $\%$ of $\mathrm{Cu}$ precursor is utilized in this study to improve packing density and electron pathway. The specimens were sintered with various IPL irradiation energies as shown in Fig. 4 and Table 5. The resistivity of the $\mathrm{Cu}$ NPs electrode and CPN electrode was the lowest when treated with an irradiation energy of $4.70 \mathrm{~J} / \mathrm{cm}^{2}$ and $5.13 \mathrm{~J} / \mathrm{cm}^{2}$, respectively. It was found that the CPN electrode had lower resistivity when the IPL energy density was over $4.46 \mathrm{~J} / \mathrm{cm}^{2}$. However, when energy densities above $4.94 \mathrm{~J} / \mathrm{cm}^{2}$ and $5.41 \mathrm{~J} / \mathrm{cm}^{2}$ were applied to $\mathrm{Cu} \mathrm{NP}$ and CPN respectively, resistivity began to increase. This was the result of oxidation on the copper electrode that formed from an excessive increase in temperature. Overall, the optimal IPL energy densities of $4.70 \mathrm{~J} / \mathrm{cm}^{2}$ and $5.17 \mathrm{~J} / \mathrm{cm}^{2}$ was selected for $\mathrm{Cu}$ NPs and CPN electrodes, respectively based on the lowest resistivity readings.

The lowest resistivity of $19.98 \mu \Omega \cdot \mathrm{cm}$ was observed at the optimum IPL energy density $\left(4.70 \mathrm{~J} / \mathrm{cm}^{2}\right)$ for the Cu NP electrode. On the other hand, the optimum IPL energy of CPN electrodes was found to be higher than that of $\mathrm{Cu}$ NP electrodes. This was due to a higher energy requirement for thermal decomposition of the $\mathrm{Cu}$ precursor. The CPN electrode showed the lowest resistivity of $12.2 \mu \Omega \cdot \mathrm{cm}$ at its optimal IPL energy density $\left(5.17 \mathrm{~J} / \mathrm{cm}^{2}\right)$. This indicated that the voids between $\mathrm{Cu}$ particles were filled with $\mathrm{Cu}$ seed precipitated from thermal decomposition of $\mathrm{Cu}$ precursor. The thermal decomposition of $\mathrm{Cu}$ precursor and reduction of oxides is presented in the following equations: 


\begin{tabular}{|l|l|l|l|}
\hline IPL voltage $(\mathbf{V})$ & IPL energy density $\left(\mathbf{J} / \mathbf{c m}^{2}\right)$ & Resistivity of Cu NPs electrode $(\boldsymbol{\mu} \Omega \cdot \mathbf{c m})$ & Resistivity of CPN electrode $(\boldsymbol{\mu} \Omega \cdot \mathbf{c m})$ \\
\hline 1900 & 3.04 & $2406.21( \pm 277.78)$ & - \\
\hline 2000 & 3.28 & $431.10( \pm 58.33)$ & - \\
\hline 2100 & 3.51 & $125.54( \pm 25.12)$ & $2783.88( \pm 297.78)$ \\
\hline 2200 & 3.75 & $69.99( \pm 13.89)$ & $339.43( \pm 52.78)$ \\
\hline 2300 & 3.99 & $42.21( \pm 8.33)$ & $153.32( \pm 19.44)$ \\
\hline 2400 & 4.22 & $28.32( \pm 2.78)$ & $44.99( \pm 8.33)$ \\
\hline 2500 & 4.46 & $22.77( \pm 1.94)$ & $19.71( \pm 1.71)$ \\
\hline 2600 & 4.70 & $19.98( \pm 0.56)$ & $13.60( \pm 1.11)$ \\
\hline 2700 & 4.94 & $31.10( \pm 2.78)$ & $12.93( \pm 0.83)$ \\
\hline 2800 & 5.17 & $67.21( \pm 8.33)$ & $12.20( \pm 0.28)$ \\
\hline 2900 & 5.41 & $347.77( \pm 53.83)$ & $16.93( \pm 5.56)$ \\
\hline 3000 & 5.65 & $2606.32( \pm 127.78)$ & $44.99( \pm 13.89)$ \\
\hline 3100 & 5.88 & - & $229.43( \pm 11.11)$ \\
\hline
\end{tabular}

Table 5. IPL energy density with respect to IPL voltage at $3 \mathrm{~ms}$ pulse on-time and resistivity of Cu NPs electrode and CPN electrode for each IPL energy density.

$$
\begin{gathered}
4 \mathrm{Cu}\left(\mathrm{NO}_{3}\right)_{2} \rightarrow 4 \mathrm{CuO}+4 \mathrm{NO} \uparrow+2 \mathrm{~N}_{2} \mathrm{O} \uparrow+7 \mathrm{O}_{2} \uparrow \\
5 \mathrm{CuO}+\mathrm{CH}_{3} \mathrm{COOH} \rightarrow 3 \mathrm{Cu}+\mathrm{Cu}_{2} \mathrm{O}+2 \mathrm{H}_{2} \mathrm{O}+2 \mathrm{CO}_{2} \uparrow \\
4 \mathrm{Cu}_{2} \mathrm{O}+\mathrm{CH}_{3} \mathrm{COOH} \rightarrow 8 \mathrm{Cu}+2 \mathrm{H}_{2} \mathrm{O}+2 \mathrm{CO}_{2} \uparrow
\end{gathered}
$$

$\mathrm{Cu}^{2+}$ ion in $\mathrm{Cu}$ (II) nitrate trihydrate was reduced to $\mathrm{Cu}$ (I) oxide and $\mathrm{Cu}$ (II) oxide step by step (Eq. 4-6) ${ }^{32,33}$. It is well documented that the reduction of $\mathrm{Cu}$ oxide proceeds by photo-thermal degradation of PVP binders ${ }^{15}$. In summary, $\mathrm{Cu}$ precursor is thermally decomposed by the heat generated by surface plasmonic resonance of $\mathrm{Cu}$ NPs by IPL irradiation and then formed into $\mathrm{Cu}$ seeds by photo-thermal degradation of PVP binder.

Through this process, CPN electrodes achieved higher electrical conductivity and packing density than $\mathrm{Cu}$ NP electrodes. Sintering CPN electrodes under optimal conditions significantly reduced internal voids, surface roughness, and achieved homogeneous surface characteristics. However, the CPN electrodes still had unsatisfactory mechanical and solder wetting properties. Therefore, Ni electroplating was performed to further lower the surface roughness of the electrode and improve its mechanical properties and solderability.

Nickel electroplating. For improved soldering on printed $\mathrm{Cu}$ electrodes, surface roughness and internal voids should be minimized to create a homogeneous surface. The use of $\mathrm{Cu}$ precursors helped fill the internal voids in the $\mathrm{Cu}$ NP electrodes and helped to decrease the surface roughness compared to when only Cu NPs were used $^{25}$. The improvement of packing density and surface roughness by addition of $\mathrm{Cu}$ precursor is specified in Fig. 7 and Table 9 for comparison with Ni-electroplated CPN electrode.

To further improve surface properties, Ni-electroplating was utilized. Prior to the experiment, FEM simulation was performed to predict the degree of smoothening of the CPN electrode at various Ni electroplating conditions.

FEM simulation was conducted with an important characteristic/assumptions: the shape of the Cu electrode was approximated as shown in Fig. 3. The electroplating time required for the simulated Ni deposit surface to reach an RMS value below $0.01 \mu \mathrm{m}$ is taken as the time required for successful smoothening of the electrode surface, or flattened time.

The thickness and smoothness of the Ni layer for each condition was simulated and presented graphically as shown in Fig. 5a,b. In Fig. 5a, the electrolyte potential is visualized with a contour image at a given electroplating condition ( $\# 1$; temperature, $40^{\circ} \mathrm{C}$; current density, $2 \mathrm{~A} / \mathrm{dm}^{2}$ ). As the time progresses, the potential of the electrolyte gradually decreased and the $\mathrm{Ni}^{+}$ions in the electrolyte were deposited on the cathode electrode. As shown in Fig. 5b, the roughness of the cathode gradually decreases as $\mathrm{Ni}$ is electroplated. For each of the 3 roughness types (\#1, \#2,\#3) (Fig. 3b-d, Table 3), the simulation proceeded under the conditions of 3 current densities (2, $\left.5,10 \mathrm{~A} / \mathrm{dm}^{2}\right)$ and 3 temperatures $\left(40,50,60^{\circ} \mathrm{C}\right)$.

The flattened time for each condition is presented as 3D surface graphs (Fig. 5c-e, Table 6). As the surface roughness increased $(\# 1 \rightarrow \# 3$ ), it was found that the time for the cathode to be flattened increased in all conditions. In addition, it was observed that the flattened time rapidly decreased as the current density increased $(2 \rightarrow$ $5 \rightarrow 10 \mathrm{~A} / \mathrm{dm}^{2}$ ). This is due to the faster transport of Ni ions in the electrolyte to the cathode surface at increasing current densities. Furthermore, it was found that temperature did not significantly affect the flattened time.

The thickness of the Ni electroplated layer is shown in a 3D graph after a constant period of $30 \mathrm{~s}$ (Fig. $5 \mathrm{f}-\mathrm{h}$, Table 7). It was found that as the surface roughness increased, the thickness of the plated Ni layer increased significantly. If the area to be plated with $\mathrm{Ni}$ decreases relatively quickly (smoothens), such as case \#1, the plating reaction slows. In comparison, a rough surface such as case \#3 does not achieve flattening in $30 \mathrm{~s}$; due to this, case \#3 retains its roughness and higher surface area for longer and sustains an accelerated Ni deposition process. 
(a)

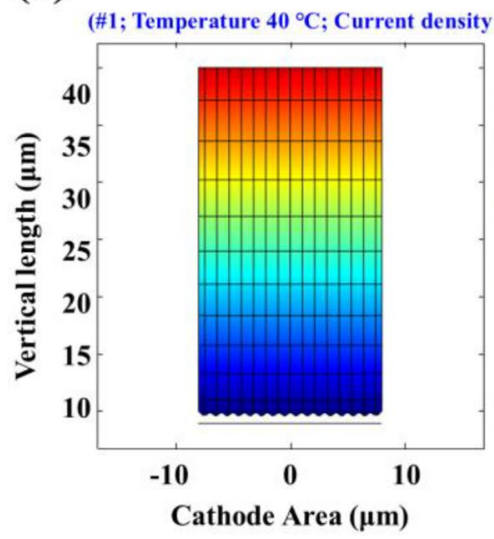

(c)

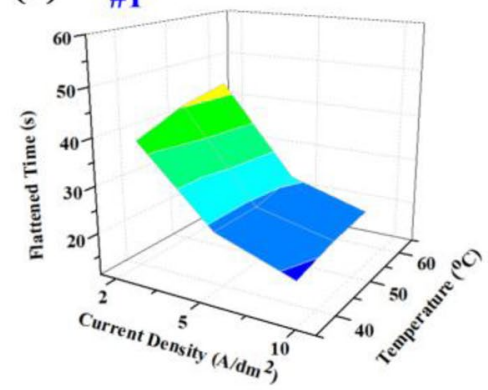

(f)

(f) \#1

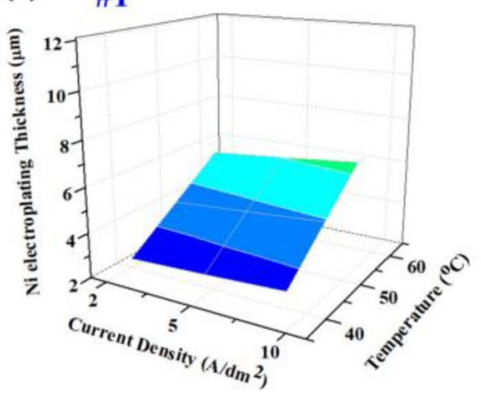

(b)

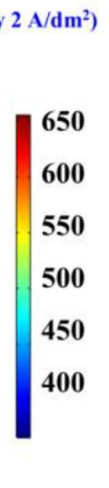

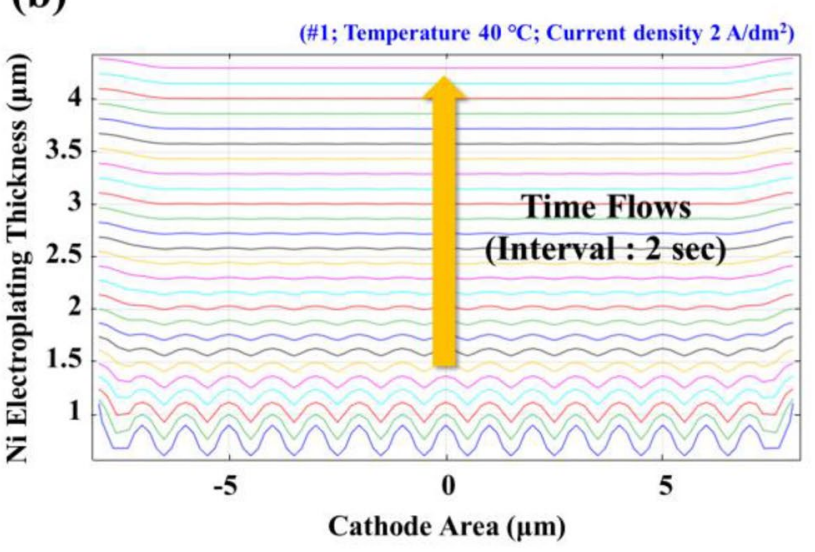

(e)

(d)

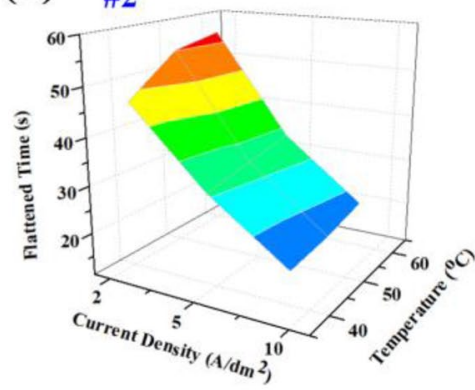

(g)

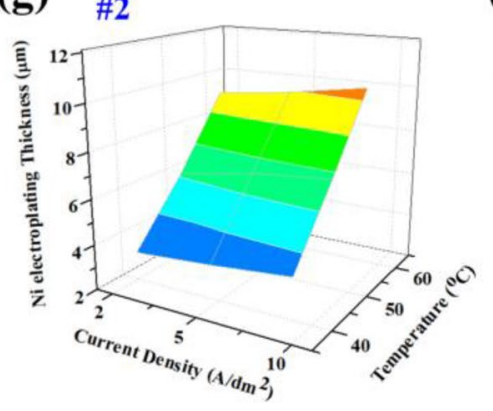

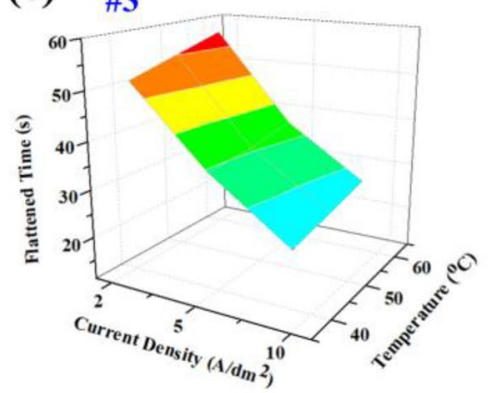

(h)

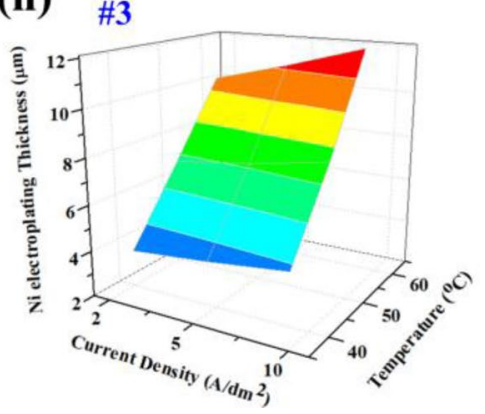

Figure 5. Multi-physics FEM simulation results. (a) the electrolyte potential contour image of \#1 geometry, (b) the thickness of electroplated Ni layer with respect to time flows with an interval of $2 \mathrm{~s}$. Time result when the cathode of (c) \#1, (d) \#2, (e) \#3 geometry becomes flat under each current density and temperature condition. The thickness results of the electroplated cathode of $(\mathbf{f}) \# 1,(\mathbf{g}) \# 2,(\mathbf{h}) \# 3$ geometry after a fixed time of $30 \mathrm{~s}$.

\begin{tabular}{|c|c|c|c|c|c|c|c|c|c|c|}
\hline \multirow{3}{*}{\multicolumn{2}{|c|}{ Time (s) }} & \multicolumn{9}{|c|}{ Temperature $\left({ }^{\circ} \mathrm{C}\right)$} \\
\hline & & \multicolumn{3}{|c|}{$\# 1$} & \multicolumn{3}{|l|}{$\# 2$} & \multicolumn{3}{|l|}{$\# 3$} \\
\hline & & 40 & 50 & 60 & 40 & 50 & 60 & 40 & 50 & 60 \\
\hline \multirow{3}{*}{ Current Density $\left(\mathrm{A} / \mathrm{dm}^{2}\right)$} & 2 & 38 & 42 & 44 & 46 & 54 & 56 & 51 & 54 & 57 \\
\hline & 5 & 22 & 22 & 24 & 30 & 32 & 34 & 35 & 36 & 38 \\
\hline & 10 & 16 & 18 & 19 & 18 & 19 & 21 & 23 & 25 & 27 \\
\hline
\end{tabular}

Table 6. Simulated flattened time of cathodes \#1, \#2, and \#3 at various current densities and temperatures.

In addition, temperature increase also increased the deposit thickness; the effect of temperature on thickness is contrasted with its limited effect in flattened time. Overall, an increase in the Ni deposit thickness indicated a growth in plated Ni particle size. As the size of the Ni particles increases, the voids between Cu particles can be quickly filled. However, if plating is allowed to continue after flattened time, excessive Ni growth will begin to increase overall roughness.

Based on the simulations, it was demonstrated that the current density is related to the Ni electroplating speed, and the temperature is related to the size of the Ni particles. Therefore, after identifying these phenomena, 


\begin{tabular}{|c|c|c|c|c|c|c|c|c|c|c|}
\hline \multirow{3}{*}{\multicolumn{2}{|c|}{ Thickness $(\mu \mathrm{m})$}} & \multicolumn{9}{|c|}{ Temperature $\left({ }^{\circ} \mathrm{C}\right)$} \\
\hline & & \multicolumn{3}{|c|}{$\# 1$} & \multicolumn{3}{|l|}{$\# 2$} & \multicolumn{3}{|l|}{$\# 3$} \\
\hline & & 40 & 50 & 60 & 40 & 50 & 60 & 40 & 50 & 60 \\
\hline \multirow{3}{*}{ Current Density $\left(\mathrm{A} / \mathrm{dm}^{2}\right)$} & 2 & 2.40 & 2.55 & 2.73 & 3.25 & 3.50 & 3.83 & 3.6 & 3.9 & 4.3 \\
\hline & 5 & 3.95 & 4.20 & 4.45 & 5.90 & 6.50 & 6.83 & 6.8 & 7.2 & 7.8 \\
\hline & 10 & 5.50 & 5.80 & 6.15 & 9.10 & 9.50 & 10.1 & 10.1 & 11.0 & 12.0 \\
\hline
\end{tabular}

Table 7. Simulated final thickness of the electroplated cathodes \#1, \#2, and \#3 after a fixed time of $30 \mathrm{~s}$.

\begin{tabular}{|c|c|c|c|c|c|c|c|}
\hline \multirow[b]{2}{*}{ Expt. no } & \multicolumn{3}{|l|}{ Factors } & \multirow[b]{2}{*}{$\begin{array}{l}\text { Resistivity } \\
(\mu \Omega \cdot \mathrm{cm})\end{array}$} & \multirow{2}{*}{$\begin{array}{l}\text { Surface } \\
\text { Roughness }\left(\mathrm{S}_{\mathbf{q}}\right) \\
(\mu \mathrm{m})\end{array}$} & \multirow[b]{2}{*}{$\begin{array}{l}\text { Thickness of Ni } \\
(\mu \mathrm{m})\end{array}$} & \multirow[b]{2}{*}{ Adhesion } \\
\hline & $\begin{array}{l}\text { Bath temperature } \\
\left({ }^{\circ} \mathrm{C}\right)\end{array}$ & $\begin{array}{l}\text { Current density } \\
\left(\mathrm{A} / \mathbf{d m}^{2}\right)\end{array}$ & Time (min) & & & & \\
\hline S-1 & 40 & 2 & 1 & 38.20 & 3.90 & 2.22 & $3 \mathrm{~B}$ \\
\hline S-2 & 40 & 2 & 3 & 32.36 & 3.44 & 3.51 & $4 \mathrm{~B}$ \\
\hline S-3 & 40 & 2 & 5 & 21.96 & 3.29 & 3.82 & $5 \mathrm{~B}$ \\
\hline S-4 & 40 & 5 & 1 & 29.68 & 3.28 & 3.51 & $4 \mathrm{~B}$ \\
\hline S-5 & 40 & 5 & 3 & 19.01 & 2.67 & 5.01 & $2 \mathrm{~B}$ \\
\hline S-6 & 40 & 5 & 5 & 12.68 & 2.47 & 7.35 & $1 \mathrm{~B}$ \\
\hline S-7 & 40 & 10 & 1 & 32.34 & 1.67 & 5.74 & OB \\
\hline S-8 & 40 & 10 & 3 & 10.54 & 2.28 & 6.36 & 0B \\
\hline S-9 & 40 & 10 & 5 & 8.964 & 2.74 & 6.55 & OB \\
\hline S-10 & 60 & 2 & 1 & 45.52 & 4.56 & 2.98 & $5 \mathrm{~B}$ \\
\hline S-11 & 60 & 2 & 3 & 38.01 & 4.07 & 4.79 & 5B \\
\hline S-12 & 60 & 2 & 5 & 24.31 & 3.43 & 5.63 & $5 \mathrm{~B}$ \\
\hline S-13 & 60 & 5 & 1 & 30.63 & 3.57 & 5.67 & $5 \mathrm{~B}$ \\
\hline S-14 & 60 & 5 & 3 & 18.27 & 2.58 & 7.84 & $3 \mathrm{~B}$ \\
\hline S-15 & 60 & 5 & 5 & 10.44 & 2.19 & 11.46 & $1 \mathrm{~B}$ \\
\hline S-16 & 60 & 10 & 1 & 14.78 & 1.45 & 5.41 & $5 \mathrm{~B}$ \\
\hline S-17 & 60 & 10 & 3 & 14.23 & 2.29 & 10.45 & $1 \mathrm{~B}$ \\
\hline S-18 & 60 & 10 & 5 & 10.97 & 2.38 & 13.23 & OB \\
\hline
\end{tabular}

Table 8. Experimental results of Ni electroplating parameters on: resistivity, surface roughness, thickness, and adhesion.

experiments were performed to confirm simulation findings. As predicted based on the simulation results, if electroplating is performed under high current density and high temperature conditions, larger size particles are plated faster, and thus a flatter Ni layer can be formed in a shorter period.

Following FE simulation results, Ni electroplating experiments were conducted at several parameters. As shown in Table 8, various specimens were prepared with 3 independent electroplating variables: temperature, current density, and plating time. In addition, dependent variables: resistivity, surface roughness, thickness, and adhesion of the $\mathrm{Ni}$ layer were measured for the 18 specimen types.

The resistivity of bulk Ni is about $7 \mu \Omega \cdot \mathrm{cm}$, but when electroplated, about 3 times the resistivity has been previously observed ${ }^{34-37}$. When electroplating Ni onto a CPN electrode with an initial resistivity of $12.2 \mu \Omega \cdot \mathrm{cm}$, the electrodes final resistivity differed depending on the plating conditions. It was found that as the thickness of the Ni layer increased, the resistivity decreased and approached the initial resistivity of the CPN electrode.

In the cases of S-6, S-8, S-9, S-15, S-17 and S-18 with very thick Ni layer, the resistivity was lower than that of the initial CPN electrode. This is due to the Ni filling in the CPN electrode increasing electron pathways. However, the electroplating proceeded excessively inside of the $\mathrm{Cu}$ electrode, weakening and almost eliminating the adhesion between the electrode and the substrate. S-16 is the only case in which substrate adhesion was retained while maintaining a relatively low resistivity of $14.78 \mu \Omega \cdot \mathrm{cm}$ and a low surface roughness.

At a fixed plating time, the surface roughness, thickness, and adhesion of plated Ni all increased with increased temperatures. This is in-line with simulation results. Under the same conditions, when the temperature increased, the thickness of the Ni electroplated layer also increased (Fig. 5f-h). Additionally, increasing current density increased the thickness of the Ni deposit and formed a smoother surface. Furthermore, an increase in plating time led to an increase in thickness and a decrease in roughness.

Another phenomenon was observed by varying current density while fixing other independent variables. Increasing current density resulted in an increase of the plating's final thickness, but it also resulted in an increase to the plating's final roughness. At a higher current density of $10 \mathrm{~A} / \mathrm{dm}^{2}$, the cracks on the surface of the CPN electrode had been quickly filled by large Ni particles. Continued growth of the Ni deposits led to a high surface roughness. Over longer periods of plating time, the surface roughness would continue to increase beyond the 

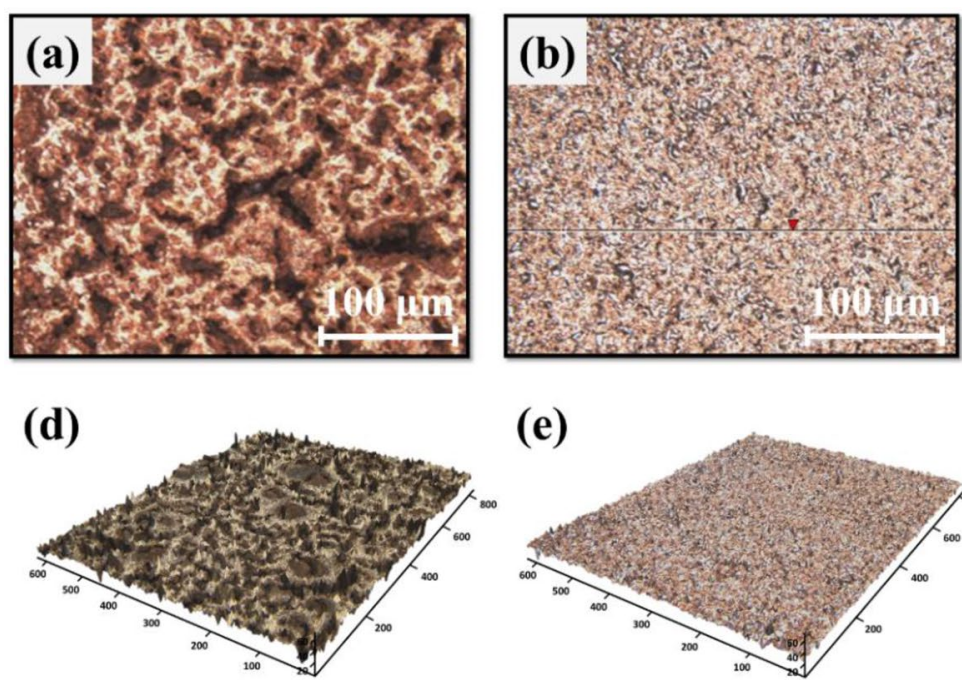

(e)

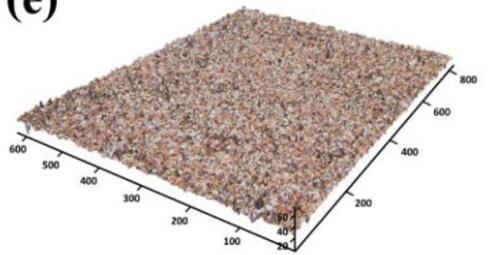

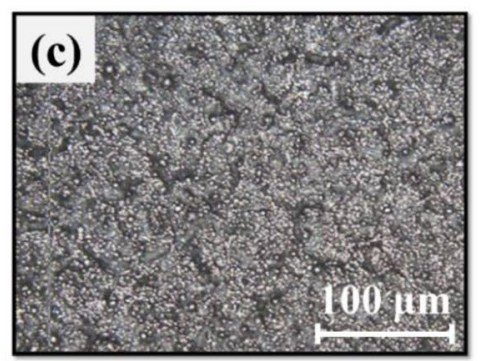

(f)

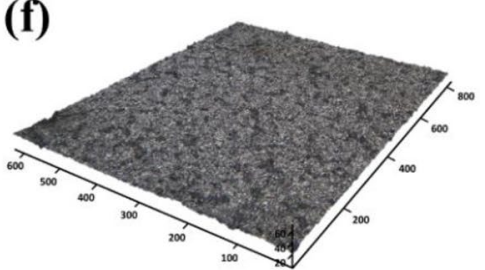

Figure 6. Surface morphology observations of (a) IPL sintered Cu NP electrode, (b) IPL sintered CPN electrode, and (c) Ni electroplated CPN electrode (S-16). Optical 3D profile images of an (d) IPL sintered Cu NP electrode, (e) IPL sintered CPN electrode, and (f) Ni electroplated CPN electrode (S-16).

\begin{tabular}{|l|l|l|l|}
\hline Label & $\begin{array}{l}\text { IPL sintered } \\
\text { Cu NP electrode }\end{array}$ & $\begin{array}{l}\text { IPL sintered } \\
\text { CPN electrode }\end{array}$ & $\begin{array}{l}\text { Ni-electroplated } \\
\text { CPN electrode (S-16) }\end{array}$ \\
\hline$S_{q}(\mu \mathrm{m})$ & $12.04 \pm 2.01$ & $3.90 \pm 0.44$ & $1.45 \pm 0.31$ \\
\hline
\end{tabular}

Table 9. Surface characterization parameters of three kinds of electrodes (Observation Area: $831 \mu \mathrm{m} \times 623 \mu \mathrm{m})$.

initial roughness of the CPN electrode. At a lower current density of $5 \mathrm{~A} / \mathrm{dm}^{2}$, it was observed that smaller $\mathrm{Ni}$ particles had gradually filled the cracks of the CPN electrodes surface and created a smooth Ni surface. The same trend occurred under all conditions, independent of temperature. In the case of S-16, electroplating was performed at a high temperature of $60^{\circ} \mathrm{C}$ and a high current density of $10 \mathrm{~A} / \mathrm{dm}^{2}$, resulting in relatively large diameter Ni particles being deposited on the electrodes surface at a high rate. Due to case S-16's low plating time of $1 \mathrm{~min}$, it was possible to fill the cracks in the CPN electrodes surface with large Ni particles while still maintaining a relatively low surface roughness. In the cases of S-17 and S-18, which had proceeded for more than $3 \mathrm{~min}$, the Ni growth formed was excessively thick and as a result, the electrodes final roughness had drastically increased. In addition to the increased roughness, $\mathrm{Ni}$ had been deposited inside the electrode, leading to an inhibition of adhesion to occur between the CPN and the substrate. In summary, the S-16 specimen showed the best balance of surface roughness, plating thickness, and adhesion to the substrate.

Based on the superior performance of the S-16 Ni-electroplated CPN electrodes, further samples were fabricated with S-16 parameters. The S-16 Ni-electroplated CPN electrodes are compared with non-plated Cu NP electrodes and CPN electrodes. In addition, S-16 electroplating conditions were utilized for selective plating experiments. By using aluminum foil, half of the printed CPN electrode was masked then exposed to IPL sintering at the optimal $2800 \mathrm{~V} 3 \mathrm{~ms}$ on-time flash. During electroplating, alligator clips were placed at the middle junction of the two halves and immersed in the same electrolyte.

Achieving selective plating of only the sintered potion presents significant savings in circuit manufacturing time. Like negative photoresists, only the printed CPN surfaces exposed to IPL irradiation will accommodate $\mathrm{Ni}$ plating. This can be utilized to create re-usable patterned masks with the desired circuit pattern to be plated. Under S-16 conditions, Ni plating was not observed in the non-sintered portion of the electrode while the sintered half plated normally. As expected, the non-conductive portion is unable to accommodate the negative charge provided by the power supply potential. This lack of conductivity meant the non-sintered portion could not participate in the reduction of Ni cations onto its surface. After over $5 \mathrm{~min}$ of plating time at S-16 conditions, the non-sintered portion exhibited no Ni-deposition. Furthermore, the non-sintered portion lost adhesion to the substrate and coherency while in the electrolyte. Simple shaking was able to remove the non-sintered portion, leaving behind a robust selectively Ni-plated CPN electrode.

Using a 3D optical profiler, the surface roughness of three kinds of electrodes were compared (Fig. 6). Pure $\mathrm{Cu}$ NP electrodes had a significantly higher surface roughness of $S_{q}=12.04 \mu \mathrm{m}$, as shown in Fig. 6a, and Table 9. Alternatively, the surface roughness of the CPN electrode was reduced to $S_{q}=3.90 \mu \mathrm{m}$ as a result of Cu seeds that filled the voids between $\mathrm{Cu}$ particles. In addition, when Ni electroplating was performed on the CPN electrode, its surface roughness was drastically reduced to $S_{q}=1.45 \mu \mathrm{m}$. 

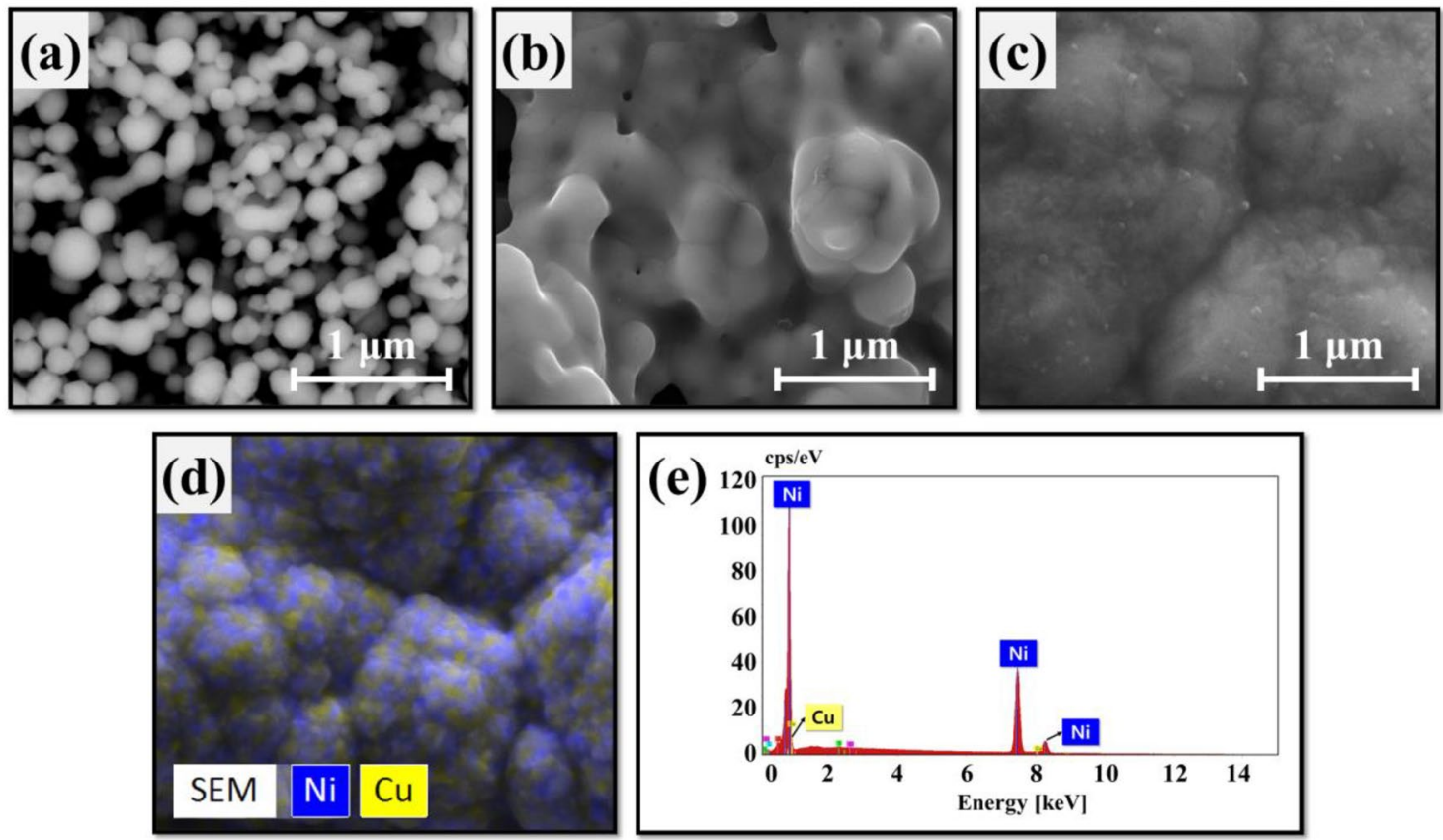

Figure 7. SEM analysis of an (a) IPL sintered Cu NPs electrode, (b) IPL sintered CPN electrode, and (c) Ni electroplated CPN electrode (S-16). (d) EDS mapping for a Ni electroplated CPN electrode and an (e) EDS spectrum for Ni electroplated CPN electrode (S-16).

The changes in roughness were observed in further detail through SEM analysis. Figure 7a shows the surface of IPL sintered $\mathrm{Cu}$ NPs. Although necking occurred between the particles, there were many voids and cracks still present between these particles. On the other hand, as seen in Fig. $7 \mathrm{~b}$, when $\mathrm{Cu}$ seeds are used as the precursor, the connections between $\mathrm{Cu}$ NPs are much larger, resulting in a more densely sintered material. Finally, in the case of Fig. 7c, it was observed that the Ni plated surface was smooth relative to the other electrodes.

EDS analysis was performed to confirm that $\mathrm{Ni}$ was uniformly deposited onto the surface of the CPN electrode. Figure 7d shows the EDS mapping for the distribution of $\mathrm{Cu}$ and Ni while Fig. 7e shows the corresponding EDS spectrum. On the EDS map, the blue Ni component is shown to cover the entire surface, with the yellow $\mathrm{Cu}$ component being detected in between the Ni layer. However, when this was examined by the EDS spectrum, the detected $\mathrm{Cu}$ peak was relatively negligible compared to the detected $\mathrm{Ni}$ peak. From this, the conclusion was drawn that the Ni layer covers the majority of the CPN electrode.

To demonstrate the densification of each electrode, SEM images were processed by adjusting the brightness of the images. Through the emphasized contrast between black and white, solids were represented by white regions and the voids were represented by black regions. The densification of the electrode was estimated by finding the ratio of the number of white pixels in the images to the total number of pixels in the image. $79.4 \%$ of the 336,788 total pixels were white in the processed Cu NP electrode image, while $98.6 \%$ of the 336,788 total pixels were white in the CPN electrode image. It was therefore concluded that the voids within the Cu NP electrodes were decreased from 20.6 to $1.4 \%$ when the $\mathrm{Cu}$ precursor was added. In the case of the Ni-plated CPN electrode, $100 \%$ of the 336,788 pixels in the image were white, indicating that the voids within the electrode had been filled in. It was demonstrated that voids present between $\mathrm{Cu}$ NPs could be largely eliminated by subjecting $\mathrm{Ni}$ electroplating to CPN electrodes.

These results were further confirmed through cross-sectional observation of three kinds of electrodes (Fig. 8). Each specimen was immersed in liquid nitrogen for $10 \mathrm{~min}$ and then split to expose their cross-sections and observe them through an optical microscope. The cross section of the $\mathrm{Cu} N \mathrm{NP}$ electrode revealed that the particles within were sintered, but many voids between the particles were still observed (Fig. 8a). In the case of the CPN electrode, its porosity was reduced due to the $\mathrm{Cu}$ seeds that filled the voids between $\mathrm{Cu}$ NPs, while also retaining a smooth surface (Fig. 8b). As shown in Fig. 8c, it was observed that the Ni plated CPN electrode was covered in a homogenous Ni layer. In addition, it was observed that the Ni layer penetrated the inside of the Ni plated $\mathrm{CPN}$ electrode and filled the fine cracks of the CPN electrode. Therefore, it can be inferred that the entire surface of $\mathrm{Cu}$ is covered with $\mathrm{Ni}$, and a strong bonding force acts between the interfaces. Since a homogeneous layer of $\mathrm{Ni}$ metal has formed on the surface, the Ni plated CNP electrode was theorized to have better solder adhesion.

In order to perform as a solderable electrode, there must be a strong bonding force between the solder-Ni layer and the Ni layer-CPN electrode. Therefore, ASTM D3359 adhesion testing was performed on three electrodes: Cu NPs (Fig. 9a), CPN (Fig. 9b) and Ni-electroplated CPN (Fig. 9c). In the case of the Cu NP electrode, the solderelectrode bonding strength was too weak to form a viable connection due to its rough surface and high porosity. During the adhesion test, more than $35 \%$ of the grids surface area flaked off, indicating $2 \mathrm{~B}$ adhesion. In the case of the CPN electrode, it was found that over $15 \%$ of the grids surface area gradually flaked off, indicating $3 \mathrm{~B}$ 

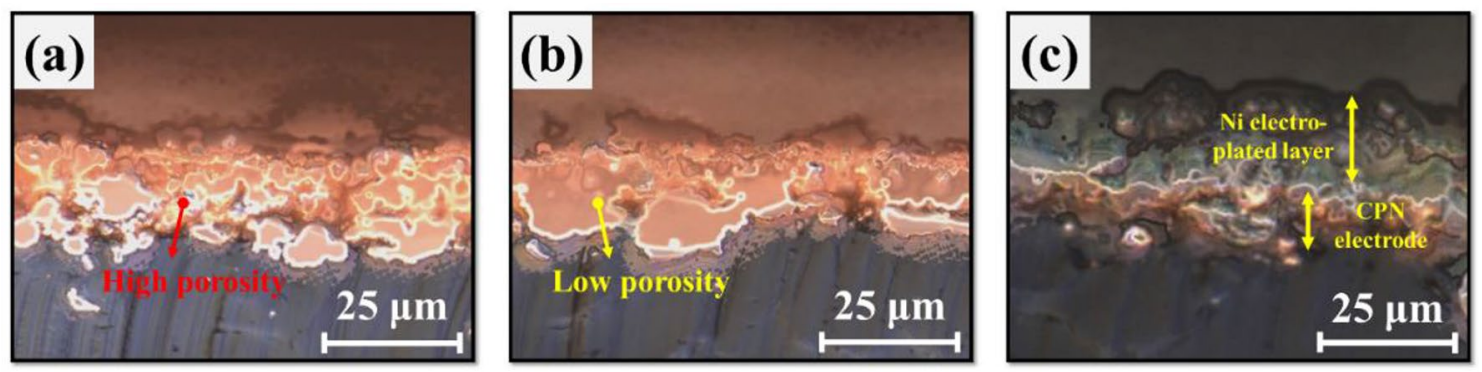

Figure 8. Cross-sectional observation of an (a) IPL sintered Cu NPs electrode, (b) IPL sintered CPN electrode, and (c) Ni electroplated CPN electrode (S-16).
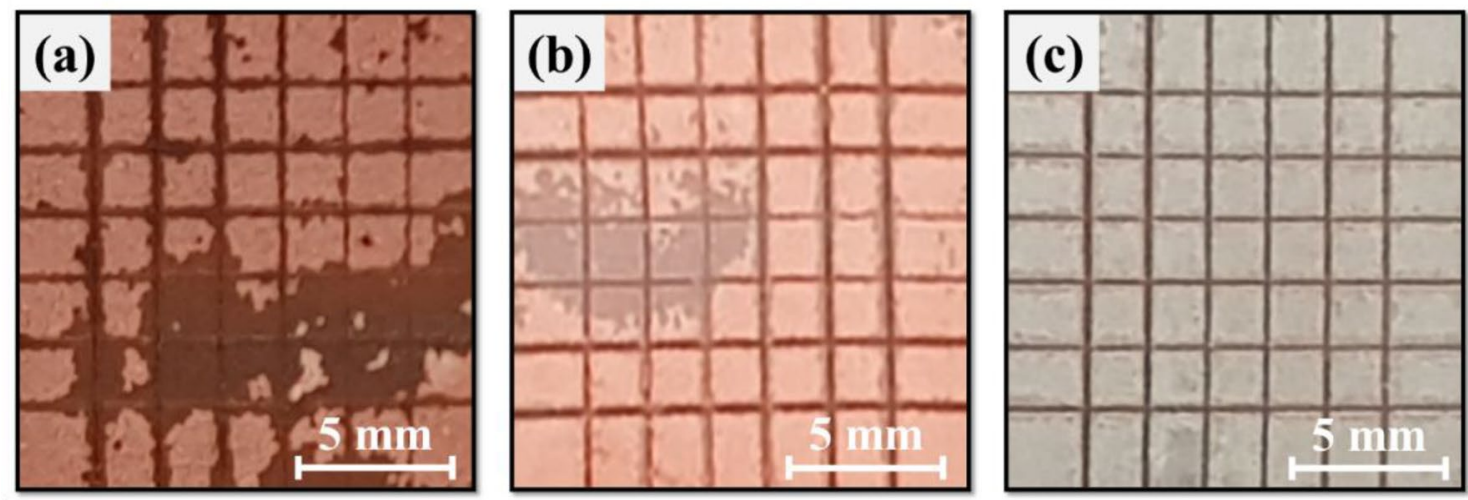

Figure 9. ASTM D 3359 Adhesion test for an (a) IPL sintered Cu NP electrode, (b) IPL sintered CPN electrode, and (c) Ni electroplated CPN electrode (S-16).
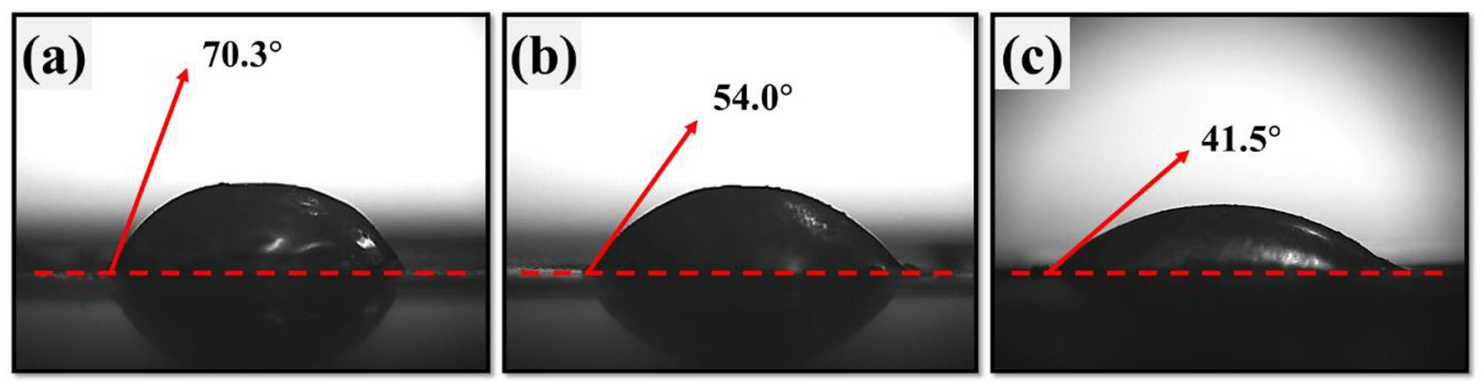

Figure 10. Solder contact angle measurement of an (a) IPL sintered Cu NPs electrode, (b) IPL sintered CPN electrode, and (c) Ni electroplated CPN electrode (S-16).

adhesion. In the case of the Ni electroplated CPN electrode, the electrode completely maintained its Ni surface, indicating $5 \mathrm{~B}$ adhesion. This confirmed that both the mechanical and surface morphology characteristics of $\mathrm{Cu}$ NP electrodes can be improved through Ni electroplating treatment.

Wetting and Mechanical properties of the Ni-electroplated CPN electrode. To investigate the solderability of Ni-electroplated CPN electrodes, wetting and solder shear tests were conducted. The wetting test was conducted by melting $1 \mathrm{~cm}$ of solder wire with a soldering iron, dropping the solder onto the electrode, and then measuring the contact angle between the solder and the electrode. As shown in Fig. 10a, the solder dropped onto the $\mathrm{Cu} \mathrm{NP}$ electrode retained a relatively low-width elliptic shape resulting in a contact angle of $70.3^{\circ}$ between the solder and the electrode. In comparison, the CPN electrode retained a contact angle of $54.0^{\circ}$ between the solder and the electrode as shown on Fig. 10b. The Ni-electroplated CPN electrode exhibited the most solder-wet behaviour with an even further decreased contact angle of $41.5^{\circ}$ between the solder and the electrode as shown in Fig. 10c. The decreased surface roughness and homogenous Ni surface was attributed for the improved solder wetting properties of the electroplated CPN electrode.

Shear tensile testing was performed to quantitatively determine the bonding strength between solder and the electrode. Solder shear strength was measured using a tensile tester as shown in Fig. 11. Through this experiment, 


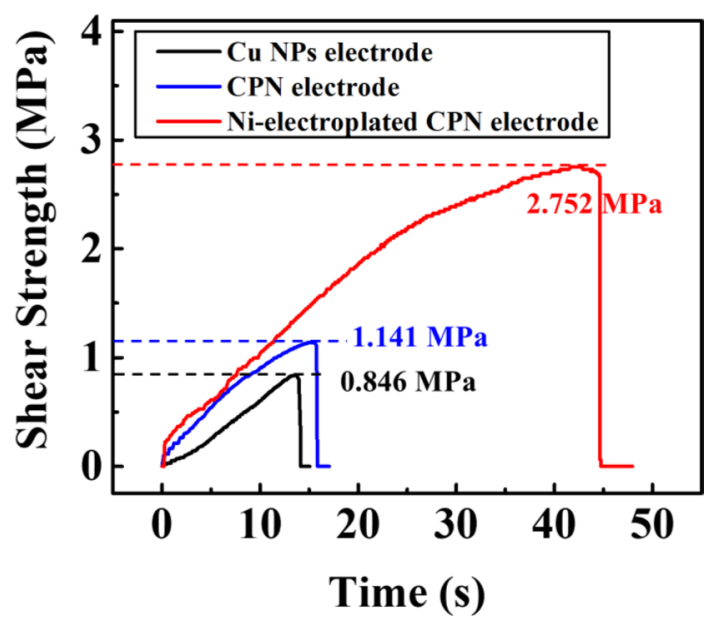

Figure 11. Shear strength tensile test between solder and electrodes. Ni-electroplating was performed under S-16 conditions.

the relationship between the electrode's treatment and the electrodes solder wettability was determined. The highest maximum shear strength of solder was observed on the Ni-electroplated CPN electrodes at 2.75 MPa. Based on these experimental results, it was confirmed that the mixing of $\mathrm{Cu}$ precursor and $\mathrm{Ni}$ electroplating significantly lowered the roughness of the electrode surface, and thus significantly increased its bonding strength with the solder. This is attributed to an increase in the electrodes solder wetting properties, resulting in a higher contact area and thus, a stronger solder connection.

Through the present investigations, sintering and electroplating parameters were optimized at $2800 \mathrm{~V}$ and S-16 conditions, respectively. IPL sintering at $2800 \mathrm{~V}$ provided the necessary energy required to sufficiently sinter the printed electrodes while avoiding excessive oxidation at higher energies. The addition of $\mathrm{Cu}$ precursor was found to improve conductivity by seeding $\mathrm{Cu}$ and increasing the overall packing density and electron pathway. Electroplating at higher temperatures $\left(60^{\circ} \mathrm{C}\right)$ and current density $\left(10 \mathrm{~A} / \mathrm{dm}^{2}\right)$ facilitated rapid void filling. Limiting the plating time to $1 \mathrm{~min}$ avoided excessive Ni growth which would increase surface roughness at longer electroplating times. Selective electroplating was demonstrated by utilizing a simple mask during IPL sintering to create conductive and electroplating surfaces while rejecting non-sintered portions (Fig. 2).

By utilizing $\mathrm{Cu}$ precursors and electroplating: solderability, adhesion, and mechanical strength was improved to produce a robust and conductive electrode. An important detail to note is that the Ni electroplated CPN electrode shearing test did not fail between the solder and the Ni surface, nor between the Ni surface and the CPN electrode. In fact, the shear test failed between the CPN electrode and the PI substrate. From this observation, it was concluded that the solderability was maximized for this type of electrode without further improvements to adhesion between the electrode and the substrate. Although chosen for its mechanical and electrical properties, there are other alternative plating metals instead of Ni. Future works can be performed to explore alternative plating metals to reduce cost while retaining the mechanical and conductive properties of Ni plated CPN electrodes.

\section{Conclusions}

We investigated the feasibility of nickel plating on IPL sintered hybrid copper electrodes. The analytical and experimental tests were conducted to observe the morphology characteristics of different electrodes to improve the solderability of printed Cu electrodes. Cu NPs were mixed with $30 \mathrm{wt} . \%$ of $\mathrm{Cu}$ (II) Nitrate Trihydrate precursor to fabricate the $\mathrm{Cu}$ Precursor/NPs (CPN) electrodes. It was found that the resistivity of the CPN electrodes was decreased due to the reduction and precipitation of $\mathrm{Cu}$ precursor between $\mathrm{Cu}$ NPs. Ni electroplating process was applied to complement the weak mechanical properties of IPL sintered $\mathrm{Cu}$, which further improved the surface morphology characteristics and improved solderability. Through multi-physics FEM electroplating simulations, effects of different parameters on electroplating were identified. Based on the mechanistic insight provided by simulation results, $\mathrm{Ni}$-electroplating was performed for improved solderability and mechanical properties. The surface roughness was drastically reduced to $S_{q}=1.45 \mu \mathrm{m}$ in optimized conditions (temperature, $60{ }^{\circ} \mathrm{C}$; cathode current density, $10 \mathrm{~A} / \mathrm{dm}^{2}$; plating time, $1 \mathrm{~min}$ ). Experimental solder shear tensile test showed a shear strength of Ni-electroplated $\mathrm{Cu}$ NPs/Precursor electrodes as $2.75 \mathrm{MPa}$. Reducing the roughness on a surface through Ni-electroplating leads to improved solder wetting. Moreover by applying a mask during IPL sintering, the electrode showed selective nickel plating only on the sintered portion (i.e., the conductive region); this paves the new way for patterned mask flashing followed by selective electroplating to streamline the circuit manufacturing process. It is expected that the proposed approach can also be used in reflow soldering of electrical components for IPL based printed electrodes and circuits.

Received: 2 March 2021; Accepted: 23 June 2021

Published online: 15 July 2021 


\section{References}

1. Subramanian, V. et al. Progress toward development of all-printed RFID tags: Materials, processes, and devices. Proc. IEEE 93, $1330-1338$ (2005).

2. David, M., Ranasinghe, D. C. \& Larsen, T. In 2011 IEEE International Conference on RFID. 176-183 (IEEE).

3. Comiskey, B., Albert, J. D., Yoshizawa, H. \& Jacobson, J. An electrophoretic ink for all-printed reflective electronic displays. Nature 394, 253-255 (1998)

4. Zyung, T. et al. Flexible organic LED and organic thin-film transistor. Proc. IEEE 93, 1265-1272 (2005).

5. Kondo, Y., Tanabe, H. \& Otake, T. Novel electrochromic polymer for electronic paper. IEICE Trans. Electron. 93, 1602-1606 (2010).

6. Yang, Y. \& Heeger, A. Polyaniline as a transparent electrode for polymer light-emitting diodes: Lower operating voltage and higher efficiency. Appl. Phys. Lett. 64, 1245-1247 (1994).

7. Haight, R. A. \& Troutman, R. R. (Google Patents, 1998).

8. Leem, D. S. et al. Efficient organic solar cells with solution-processed silver nanowire electrodes. Adv. Mater. 23, 4371-4375 (2011).

9. Zou, J., Yip, H.-L., Hau, S. K. \& Jen, A.K.-Y. Metal grid/conducting polymer hybrid transparent electrode for inverted polymer solar cells. Appl. Phys. Lett. 96, 96 (2010).

10. Liao, Y. et al. Highly conductive carbon-based aqueous inks toward electroluminescent devices, printed capacitive sensors and flexible wearable electronics. RSC Adv. 9, 15184-15189 (2019).

11. Karim, N., Afroj, S., Tan, S., Novoselov, K. S. \& Yeates, S. G. All inkjet-printed graphene-silver composite ink on textiles for highly conductive wearable electronics applications. Sci. Rep. 9, 1-10 (2019).

12. El-Sayed, M. A. Some interesting properties of metals confined in time and nanometer space of different shapes. Acc. Chem. Res. 34, 257-264 (2001).

13. Link, S. \& El-Sayed, M. A. Shape and size dependence of radiative, non-radiative and photothermal properties of gold nanocrystals. Int. Rev. Phys. Chem. 19, 409-453 (2000).

14. Hartland, G. V. Coherent excitation of vibrational modes in metallic nanoparticles. Annu. Rev. Phys. Chem. 57, 403-430 (2006).

15. Ryu, J., Kim, H.-S. \& Hahn, H. T. Reactive sintering of copper nanoparticles using intense pulsed light for printed electronics. J. Electron. Mater. 40, 42-50 (2011).

16. Hwang, H.-J., Chung, W.-H. \& Kim, H.-S. In situ monitoring of flash-light sintering of copper nanoparticle ink for printed electronics. Nanotechnology 23, 485205 (2012).

17. Hwang, Y.-T., Chung, W.-H., Jang, Y.-R. \& Kim, H.-S. Intensive plasmonic flash light sintering of copper nanoinks using a bandpass light filter for highly electrically conductive electrodes in printed electronics. ACS Appl. Mater. Interfaces 8, 8591-8599 (2016).

18. Jang, Y.-R. et al. Selective wavelength plasmonic flash light welding of silver nanowires for transparent electrodes with high conductivity. ACS Appl. Mater. Interfaces. 10, 24099-24107 (2018).

19. Salam, B. \& Lok, B. In 2008 15th International Symposium on the Physical and Failure Analysis of Integrated Circuits. 1-4 (IEEE).

20. Chan, H.-J., Huang, B.-C., Wang, L.-W., Liao, K.-H. \& Lo, C.-Y. Porosity reduction in inkjet-printed copper film by progressive sintering on nanoparticles. Thin Solid Films 627, 33-38 (2017).

21. Tuck, J., Korsunsky, A. M., Davidson, R., Bull, S. J. \& Elliott, D. Modelling of the hardness of electroplated nickel coatings on copper substrates. Surf. Coat. Technol. 127, 1-8 (2000).

22. Mosayebi, S., Rezaei, M. \& Mahidashti, Z. Comparing corrosion behavior of Ni and Ni-Mo electroplated coatings in chloride mediums. Colloids Surfaces A Physicochem. Eng. Aspects 124654 (2020).

23. Liu, C.-S., Su, F.-H. \& Liang, J.-Z. Fabrication of Co-Ni-P film with excellent wear and corrosion resistance by electroplating with supercritical CO2 emulsion. Trans. Nonferrous Metals Soc. China 28, 2489-2498 (2018).

24. Zhou, H.-H. et al. Pulse electroplating of Ni-WP coating and its anti-corrosion performance. Trans. Nonferrous Metals Soc. China 28, 88-95 (2018).

25. Chung, W.-H., Hwang, H.-J. \& Kim, H.-S. Flash light sintered copper precursor/nanoparticle pattern with high electrical conductivity and low porosity for printed electronics. Thin Solid Films 580, 61-70 (2015).

26. Young, C. \& Struyk, C. Deposition of Nickel-Cobalt alloys from chloride solutions. Trans. Electrochem. Soc. 89, 383 (1946).

27. Wojciechowski, J., Baraniak, M., Pernak, J. \& Lota, G. Nickel coatings electrodeposited from watts type baths containing quaternary ammonium sulphate salts. Int. J. Electrochem. Sci. 12, 3350-3360 (2017).

28. Mattsson, E. \& Bockris, J. M. Galvanostatic studies of the kinetics of deposition and dissolution in the copper + copper sulphate system. Trans. Faraday Soc. 55, 1586-1601 (1959).

29. Lima, F., Mescheder, U. \& Reinecke, H. Simulation of current density for electroplating on silicon using a Hull cell. Solar Cells 6 , 7 (2012)

30. Yan, D. Computational Simulation of Copper (Cu) and Nickel-Copper (Ni-Cu) Alloy Electrodeposition (2019).

31. Shourije, S. \& Bahrololoom, M. Comparison of effects of simulated electric field interference and presence of a barrier in the nickel electroplating process to experimental data. Trans. IMF 98, 303-313 (2020).

32. Lee, B. et al. Hybrid copper complex-derived conductive patterns printed on polyimide substrates. Met. Mater. Int. 18, 493-498 (2012).

33. Kim, M. H., Lim, B., Lee, E. P. \& Xia, Y. Polyol synthesis of $\mathrm{Cu}_{2} \mathrm{O}$ nanoparticles: use of chloride to promote the formation of a cubic morphology. J. Mater. Chem. 18, 4069-4073 (2008).

34. Luo, J. et al. Effects of process conditions on properties of electroplated Ni thin films for microsystem applications. J. Electrochem. Soc. 153, D155 (2006).

35. Safranek, W. H. The properties of electrodeposited metals and alloys: A handbook. Am. Electroplaters Surface Finish. Soc. 1986, 550 (1986).

36. Aesar, A. (Ward Hill, MA, 2003).

37. Safranek, W. Structure and property relationships for bulk electrodeposits. J. Vac. Sci. Technol. 11, 765-770 (1974).

\section{Acknowledgements}

The authors acknowledge the financial support of the Natural Sciences and Engineering Research Council of Canada (NSERC). This work was supported by the Korea Institute of Energy Technology Evaluation and Planning(KETEP) and the Ministry of Trade, Industry \& Energy(MOTIE) of the Republic of Korea (No. 20206910100160). This research was also supported by the MOTIE (Ministry of Trade, Industry, and Energy) in Korea, under the Fostering Global Talents for Innovative Growth Program (P0008748, Global Human Resource Development for Innovative Design in Robot and Engineering) supervised by the Korea Institute for Advancement of Technology (KIAT).

\section{Author contributions}

All authors contributed to the writing and development of the manuscript. Authors Yong-Rae Jang and Robin Jeong performed data collection and analysis for all physical experiments. Author Yong-Rae Jang performed 
simulation data collection and analysis. Authors Hak-Sung Kim and Simon Park provided initial conceptual design as well as continued guidence and oversight.

\section{Competing interests}

The authors declare no competing interests.

\section{Additional information}

Correspondence and requests for materials should be addressed to H.-S.K. or S.S.P.

Reprints and permissions information is available at www.nature.com/reprints.

Publisher's note Springer Nature remains neutral with regard to jurisdictional claims in published maps and institutional affiliations.

(c) (i) Open Access This article is licensed under a Creative Commons Attribution 4.0 International License, which permits use, sharing, adaptation, distribution and reproduction in any medium or format, as long as you give appropriate credit to the original author(s) and the source, provide a link to the Creative Commons licence, and indicate if changes were made. The images or other third party material in this article are included in the article's Creative Commons licence, unless indicated otherwise in a credit line to the material. If material is not included in the article's Creative Commons licence and your intended use is not permitted by statutory regulation or exceeds the permitted use, you will need to obtain permission directly from the copyright holder. To view a copy of this licence, visit http://creativecommons.org/licenses/by/4.0/.

(C) The Author(s) 2021 